\title{
Premedication for fibreoptic bronchoscopy
}

\author{
PJ REES, JG HAY, JR WEBB \\ From the Regional Respiratory Laboratory, Brook Hospital, London
}

ABSTRACT A randomised, double-blind trial of atropine, atropine plus papaveretum, and atropine plus diazepam given intramuscularly as premedication for fibreoptic bronchoscopy in 60 patients showed no difference between the three regimens as assessed by bronchoscopist or patient. Bronchoscopists frequently attributed a sedative action to atropine alone and their assessment of tolerance and sedation was more optimistic than that of the patients. In a second study comparing intravenous diazepam $(10 \mathrm{mg})$ with saline, after prior intramuscular atropine $(0.6 \mathrm{mg})$, both the bronchoscopists and the patients noted a significant sedative effect of diazepam, and coughing was reduced by diazepam.

Premedication for fibreoptic bronchoscopy frequently consists of an intramuscular injection of an anticholinergic agent and an opiate or benzodiazepine 30-60 minutes before the procedure. The anticholinergic agent is necessary to prevent vasovagal phenomena, ${ }^{1}$ reflex bronchoconstriction, and bradycardia. It also helps to decrease secretions in the pharynx and airways. Opiates are given both for their antitussive effect and for sedation and a combination of anticholinergic agent and opiate is often used as premedication before general anaesthesia.

Because of dissatisfaction with this regimen we compared the effects of atropine alone and in combination with either diazepam or papaveretum in 60 consecutive patients undergoing fibreoptic bronchoscopy. Since the study showed that none of these three combinations was satisfactory, we went on to assess the use of diazepam given intravenously at the time of the bronchoscopy.

\section{Methods}

INTRAMUSCULAR ATROPINE, DIAZEPAM, AND PAPAVARETUM

Sixty consecutive patients considered fit to have any of the three premedications were studied. All received $0.6 \mathrm{mg}$ atropine, 20 received $10 \mathrm{mg}$ diazepam, and 20 received 10,15 , or $20 \mathrm{mg}$ of papaveretum, depending on weight and age $(10 \mathrm{mg}$

Address for reprint requests: Dr PJ Rees, Respiratory Function Laboratory, Guy's Hospital, London SE1 9RT.

Accepted 20 April 1983
$<50 \mathrm{~kg}, 15 \mathrm{mg} 50-70 \mathrm{~kg}$ or $>65$ years, $20 \mathrm{mg}>70$ $\mathrm{kg}$ and $<65$ years). All drugs were given intramuscularly 20-40 minutes before patients came to the bronchoscopy suite. Patients and bronchoscopists were unaware of the premedication given, the order being randomised and chosen from a set of sealed envelopes. Topical anaesthesia was used for the oropharynx, larynx, and airways in the usual manner. ${ }^{2}$ The nasal route was used when possible, and was always attempted first. Bronchoscopy was performed with the patient supine. The same two experienced bronchoscopists performed the procedures and the assessments in both studies and in all cases an assistant was present.

Immediately after the bronchoscopy the bronchoscopist answered three questions on the sedative effect of the premedication, the extent of coughing, and the patient's tolerance. Two bronchoscopists were concerned in the assessment and each question had four possible answers (table 1). Between one and three hours after the bronchoscopy the patient completed questions on the sedative effect of the premedication and tolerance of the procedure (table 1). Patients were also asked for their opinion on the worst part of the procedure. Assessment of premedication in the first few hours after bronchoscopy has been shown to reflect accurately the subsequent attitude of the patients. ${ }^{3}$

The three premedications were compared in pairs by the Kolomgorov-Smirnov two-sample test. ${ }^{4}$

INTRAVENOUS DIAZEPAM VERSUS PLACEBO After we had obtained the results of the above study a similar double-blind comparison was made bet- 
ween an intravenous injection of diazepam $10 \mathrm{mg}$ (Diazemuls) and saline, each given at the same time as the local anaesthetic for bronchoscopy. Assessments were made in 30 patients as described above, and the six bronchoscopists were aware of the results of the first study. All the subjects received $0.6 \mathrm{mg}$ atropine intramuscularly 30 minutes before bronchoscopy.

\section{Results}

INTRAMUSCULAR ATROPINE, DIAZEPAM, AND

\section{PAPAVERETUM}

There was no significant difference between the three premedications with regard to sedative effect, tolerance, or coughing as assessed by bronchoscopist or patient (table 1 ). More or less equal numbers of patients found the broncoscopy mildly unpleasant and very unpleasant. Five of the 60 patients thought it was too unpleasant ever to be repeated. Twentysix of the 40 patients given papavaretum or diazepam detected no sedative effect; the bronchoscopists thought the sedative effects greater, and they believed the effect of atropine alone to be adequate in 14 out of 20 cases.

Seventeen of the 60 patients found passage of the bronchoscope through the larynx to be the worst part of the procedure (table 2). Anaesthesia of the larynx and coughing were other frequent answers to this question, and those who found coughing the most unpleasant part were evenly divided between the three premedications.

\section{INTRAVENOUS DIAZEPAM VERSUS PLACEBO} Bronchoscopists and patients noted a significantly greater sedative effect with diazepam than saline (Kolmogorov-Smirnov test, $p<0.01$ ). There was no significant difference in tolerance for the procedure assessed by bronchoscopists or patients, but coughing was less with diazepam $(p<0.05)$. The greatest difference from the first study was that the bronchoscopists were less likely to attribute a sedative effect to atropine alone. One patient in each group was given an extra $10 \mathrm{mg}$ intravenous diazepam during the procedure by an assistant.

\section{Discussion}

Fibreoptic endoscopy should be as comfortable as possible for the patient without increasing morbidity from excessive sedation. This is particularly important when repeated bronchoscopies may be necessary, as has been proposed for bronchoalveolar lavage in diffuse lung disease.

Table 1 Questionnaire answers from bronchoscopists and patients

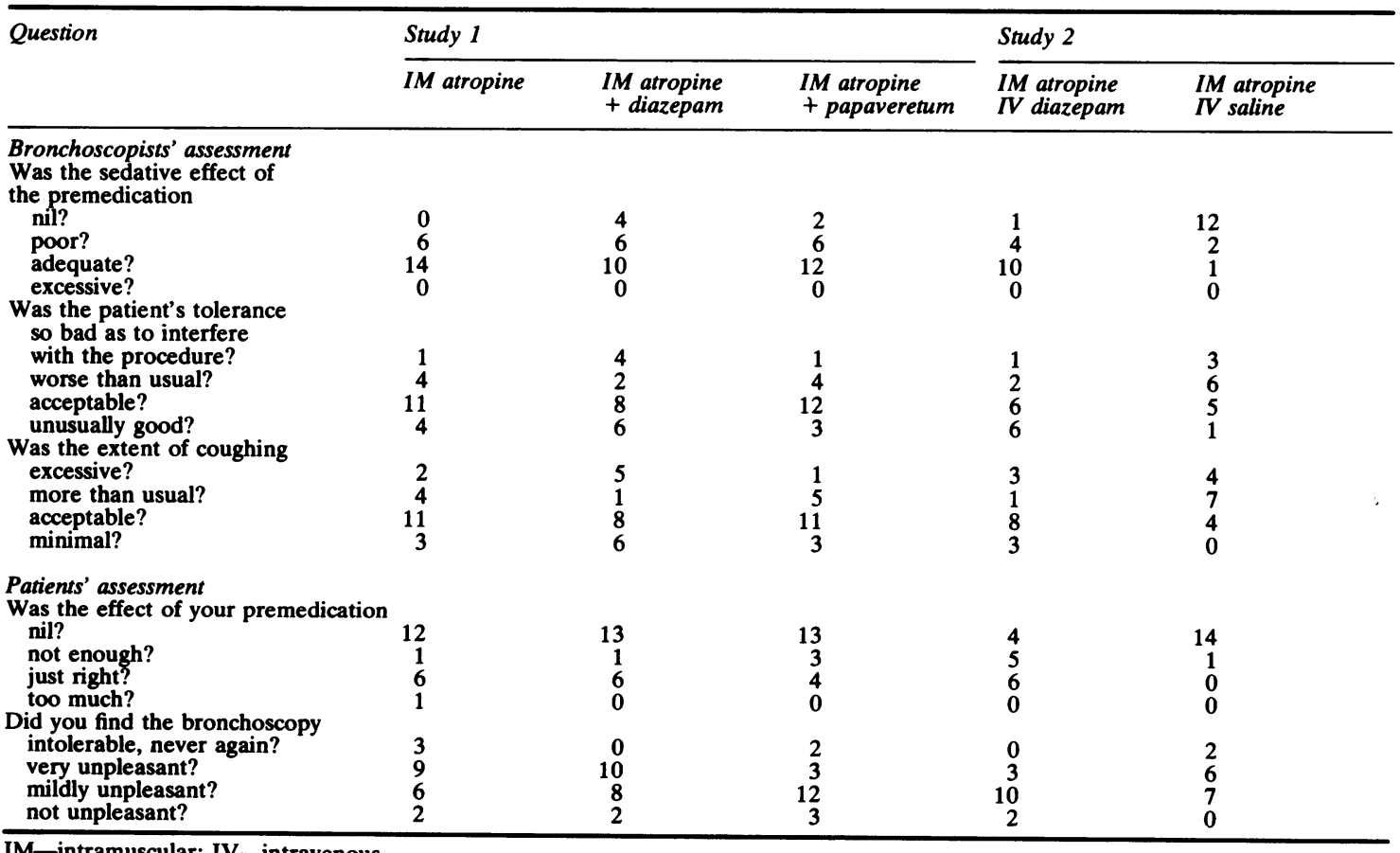

IM-intramuscular; IV-intravenous. 
Table 2 Replies from 60 patients" to the question "What was the worst part of the bronchoscopy?"

\begin{tabular}{lc}
\hline Answer & No of replies \\
Passage through larynx & 17 \\
Coughing & 14 \\
Anaesthesia of vocal cords & 9 \\
Passage through nose & 7 \\
Dyspnoea, choking sensation & 4 \\
Lignocaine in nose and mouth & 4 \\
Premedication injection & 1 \\
Haemoptysis & 1 \\
Pain from transbronchial biopsy & 1 \\
No worst part & 6 \\
\hline
\end{tabular}

*Four gave two answers.

Pearce found atropine premedication alone satisfactory for fibreoptic bronchoscopy ${ }^{5}$ but for gastroscopy the patients of Thompson and his colleagues preferred the additional sedation given by intravenous diazepam. ${ }^{6}$ Diazepam also has the advantage of an amnesic effect ${ }^{78}$ and has been found to be preferable to morphine premedication for gastroscopy. ${ }^{9}$ When used intravenously the dose can be adjusted to the individual patient's requirements. A recent study comparing oral temazepam with intramuscular papaveretum found no difference in coughing, relaxation, or consciousness but slightly less recall of the procedure after temazepam. ${ }^{10}$ Our results suggest that a placebo group might well have produced similar results. Opiate drugs might be expected to decrease coughing at bronchoscopy but this was not found in our study or in that of Dorward et al. ${ }^{10}$ Differences between studies might reflect psychological differences between patients ${ }^{3}$ or differences in the psychological preparation of the patient by bronchoscopist or other staff. ${ }^{11}$

Our initial study of three premedications was performed because of dissatisfaction with our routine premedication, which consisted of atropine and papaveretum. The results were analysed after the first 60 patients. They showed no significant difference between the premedications and disclosed much discomfort among the patients. There was a trend for patients to find the procedure less unpleasant with papaveretum (table 1). The tolerance of the procedure and the sedative effect were generally rated much worse by the patients than by the bronchoscopists. This indicates the importance of patients' opinions in such studies and shows that we often do not appreciate patients' responses to such procedures.

In the second study the bronchoscopists were less likely to attribute a sedative effect to atropine alone. This may have been because of the greater contrast with diazepam or because they adjusted their responses when aware of the results of the first study. They also appeared to be less optimistic in their assessment of patients' tolerance after atropine alone in the second study. The second study showed that intravenous diazepam at the time of broncho- $\stackrel{5}{\rightarrow}$ scopy was a useful addition to atropine alone, giving a sedative effect even with a fixed dose. The trend $\underline{\underline{F}}$ was for tolerance of the procedure to be improved $\frac{\bar{\omega}}{\vec{\alpha}}$ by diazepam; coughing was reduced; and none of $\stackrel{\mathbb{\Omega}}{\Omega}$ the patients receiving diazepam found the bronchoscopy too unpleasant to be considered again.

Anaesthesia of the vocal cords or passage of the bronchoscope through the larynx was the most $\vec{\omega}$ unpleasant part of the procedure for 26 of the $60 \stackrel{\text { }}{\circ}$ patients. We have found anaesthetising the larynx $\vec{x}$ by holding local anaesthetic in the pyriform fossae ${ }^{12} \underset{\infty}{\omega}$ to be equally unpleasant, but more controlled appli- $\stackrel{\infty}{\infty}$ cation of anaesthetic with a fine spray used locally may be more efficient. ${ }^{13}$ The patients' opinions of $\stackrel{N}{\perp}$ the most unpleasant parts of the bronchoscopy 옥 emphasise the importance of careful anaesthesia of $\overrightarrow{ }$ and passage through the upper airway.

We suggest that intravenous diazepam given during the bronchoscopy is a more satisfactory regimen $\stackrel{\infty}{\stackrel{+}{+}}$ than intramuscular papaveretum or diazepam $\vec{\omega}$ beforehand. Care must, however, be taken with $\stackrel{\infty}{\infty}$ patients at risk of respiratory depression as diazepam cannot be reversed by naloxone in the same way as opiates. We have subsequently found the combination of prior intramuscular atropine and intravenous diazepam at the time of bronchoscopy $\frac{\mathscr{Q}}{\varnothing}$ to be very satisfactory for day-case bronchoscopies.

\section{References}

${ }^{1}$ Zavala DC, Godsey K, Bedell GN. The response to atropine sulfate given by aerosol and intramuscular 으 routes to patients undergoing fibreoptic bronchos- $\stackrel{\sim}{x}$ copy. Chest 1981;79:512-5.

${ }^{2}$ Efthimiou J, Higenbottam T, Holt D, Cochrane GM. Plasma concentration of lignocaine during fibreoptic bronchoscopy. Thorax 1982;37:68-71.

${ }^{3}$ Webberley MJ, Cushieri A. Response of patients to

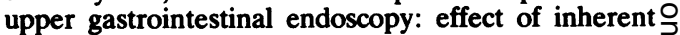
personality traits and premedication with diazepam. $\rightarrow$ Br Med J 1982;285:251-2.

4 Siegal S. Nonparametric statistics for the behavioural sciences. Tokyo: McGraw-Hill, 1956.

${ }^{5}$ Pearce SJ. Fibreoptic bronchoscopy: is sedation necessary? Br Med J 1980;281:779-80.

- Thompson DG, Lennard-Jones JE, Evans SJ, Cowan Nָ RE, Murray RS, Wright JT. Patients appreciate premedication for endoscopy. Lancet 1980;ii:469-70.

7 Anonymous. The discomforts of modern endoscopy. Lancet 1980;ii:1064.

${ }^{8}$ Brown P, Salman PR, Read AE. Premedication for gas-? trointestinal endoscopy. Lancet 1972;i:270.

${ }^{9}$ Ludlam R, Bennet JR. Comparison of diazepam andŌ morphine as premedication for gastrointestinal endos- $\overrightarrow{\mathbb{D}}$ copy. Lancet 1971;ii:1397-9.

${ }^{10}$ Dorward AJ, Barkin KE, Elliott JA, Stack BHR. A을 double-blind controlled study comparing temazepam 
with papaveretum as premedication for fibreoptic bronchoscopy. Br J Dis Chest 1983;77:60-5.

11 Johnson JE, Morrissey JF, Leventhal H. Psychological preparation for an endoscopic examination. Gastrointest Endosc 1973;19:180-2.
${ }^{12}$ Zavala DC. Bronchoscopy and cytology. In: Clark TJH, ed. Clinical investigation of respiratory disease. London: Chapman and Hall, 1981:366.

${ }^{13}$ Rees PJ. Simple device for laryngeal anaesthesia at fibreoptic bronchoscopy. Lancet 1982;ii:989. 